\section{Familial dysequilibrium-diplegia}

Sir,

The interesting report by Dr. Graham-Pole and his colleagues (Archives, 1975, 50, 927) provides evidence that the syndrome originally reported by Hagberg and his colleagues is not a chance association, and very properly distinguishes this condition from the Louis-Bar syndrome (ataxia-telangiectasia.) However, I wish to take issue with the dogmatic statement that, 'Diplegia with extensor plantars . . . is never a feature of ataxia telangiectasia ...

This is not true in my experience since a diplegic syndrome may be a somewhat misleading presenting feature of that condition before the more typical cerebellar and striatal components are evident.

JOHN WILSON

The Hospital for Sick Children, Great Ormond Street, London WC1N $3 J H$.
Dr. J. Graham-Pole and colleagues comment:

Diplegia is a somewhat loose descriptive term, and we would not dispute that the hen-toed toddler with (as yet undiagnosed) ataxia-telangiectasia (AT) resembles diplegic cerebral palsy. What we would emphasize is the absence of 'pyramidal' signs in AT. Of course, if examined sufficiently early in life the affected infant will have extensor plantars like any other baby, but as Boder and Sedgwick (1963) have emphasized, extensor plantars are not a feature of symptomatic AT, this finding being recorded in only one out of 61 documented cases.

Never?-well, hardly ever.

J. GRAHAM-POLE, A. FERGUSON,

A. A. M. GIBSON, and J. B. P. STEPHENSON Royal Hospital for Sick Children, Yorkhill, Glasgow G3 8SJ REFERENCE

Boder, E., and Sedgwick, R. P. (1963). Ataxia-telangiectasia. A review of 101 cases. Little Club Clinics in Developmental Medicine, No. 8., p. 110. Ed. by G. Walsh. Heinemann London. 